\title{
BMJ Open Protocol for the Northern babies longitudinal study: predicting postpartum depression and improving parent-infant interaction with The Newborn Behavioral Observation
}

\author{
Ragnhild Sørensen Høifødt,, ${ }^{1,2}$ Dag Nordahl, ${ }^{1,3}$ Gerit Pfuhl,, ${ }^{1,4}$ \\ Inger Pauline Landsem, ${ }^{3,5}$ Jens C Thimm, ${ }^{1}$ Linn Kathrin K Ilstad, ${ }^{2}$ \\ Catharina Elisabeth Arfwedson Wang ${ }^{1}$
}

To cite: Høifødt RS, Nordahl D, Pfuhl G, et al. Protocol for the Northern babies longitudinal study: predicting postpartum depression and improving parent-infant interaction with The Newborn Behavioral Observation. BMJ Open 2017;7:e016005. doi:10.1136/ bmjopen-2017-016005

- Prepublication history for this paper is available online. To view these files please visit the journal online (http://dx.doi org/10.1136/bmjopen-2017016005).

RSH and DN contributed equally.

Received 9 February 2017

Revised 29 June 2017

Accepted 29 June 2017

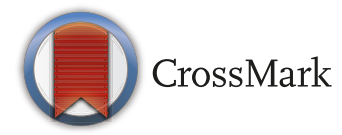

For numbered affiliations see end of article.

Correspondence to

Mr Dag Nordahl;

dag.nordah!@uit.no

\section{ABSTRACT}

Introduction Postpartum depression (PPD) is a prevalent disorder. Studying the factors related to PPD will help to identify families at risk and provide preventive interventions. This can in turn improve the developmental trajectories for the children. Several previous studies have investigated risk factors for PPD. However, few studies have focused on cognitive vulnerability factors. The first aim of the present study is to explore a range of protective and risk factors, including cognitive factors, for PPD, parent-infant interactions and child development. The second aim of the study is to evaluate the effectiveness of The Newborn Behavioral Observation (NB0) as a universal preventive intervention delivered in routine practice. The NBO is a brief relationshipenhancing intervention that may reduce depressive symptomatology in mothers.

Methods The study is a longitudinal observational study with an intervention. The observational study uses a prospective cohort design, whereas the intervention study has a non-randomised cluster-controlled design comparing a group receiving NBO with a group receiving standard care. The intervention group will receive three NB0 sessions within the first 4 weeks postdelivery.

Between 2015 and 2018, approximately 200 families will be recruited in the municipality of Troms $\emptyset$, Norway. Parents are recruited during pregnancy, and assessments will be performed during gestational weeks 16-22, 24-30 and 31 , and at 6 weeks, 4 months and 6 months postdelivery. Predictor variables include several cognitive vulnerability factors including early maladaptive schemas, implicit attitudes and cognitive processing of emotionally valenced infant facial information.

Ethics and dissemination The Regional Committee for Medical and Health Research Ethics in Northern Norway has approved the project. The research team has collaboration with local health services and can assist participants who need more extensive follow-up. Results from the project will be disseminated in international and national peer-reviewed journals, and at courses and conferences.

Trials registration number NCT02538497; Pre-results.
Strengths and limitations of this study

- This study will provide new knowledge about cognitive vulnerability and protective factors associated with postpartum depression (PPD), parent-infant interaction and child development.

- The study is the first to examine the effect of Newborn Behavioral Observation, a brief relationship-enhancing parent-infant intervention, delivered as a universal preventive intervention both for PPD and for parent-infant interaction difficulties.

- Mothers, infants and fathers are followed through six assessments; from gestational week 16-22 until 6 months postdelivery.

- A limitation of the study is that the participants are not randomly assigned to the intervention and control group, respectively.

- Further limitations are that depression is measured by self-report questionnaires only and that potentially important factors such as parental personality and other mental health variables, for example, anxiety and post-traumatic stress disorder symptoms, are not included.

\section{INTRODUCTION}

The transition into parenthood is a period with great biological and psychosocial changes and is associated with an increased risk for depressed mood for both mothers and fathers. ${ }^{1}$ The prevalence of postpartum depression (PPD) is between $10 \%$ and $15 \%$ for women, ${ }^{23}$ and between $5 \%$ and $10 \%$ for men. ${ }^{14-9}$ However, a meta-analysis suggested that the rate in men may be as high as $25 \%$ in the period between 3 and 6 months post partum. ${ }^{9}$

Important risk factors for developing maternal PPD include antenatal depression and anxiety, previous psychiatric illness, a poor marital relationship, life stressors, a 
negative attitude towards pregnancy and lack of social support. ${ }^{10}$ Adverse childhood experiences are in general considered a risk for depression ${ }^{11}$ and stress ${ }^{12}$ in adulthood. In addition, an insecure adult attachment style is shown to be related to maternal PPD. ${ }^{13}$ Paternal PPD shares many of the same risk factors as maternal PPD. ${ }^{56}$ However, the most common correlate for paternal PPD is having a depressed partner. ${ }^{814}$ Thus, depression in one parent increases the risk for couple comorbidity where both parents become depressed.

\section{COGNITION IN PPD}

Parents' ability to cope with and relate to this transitional period can be assessed by measuring their cognitive schemas and information processing. Cognition may have an important role in the development of maternal PPD and may affect the quality of mother-infant interactions. In fact, cognitive factors such as negative self-schemas, ${ }^{15}$ antenatal self-devaluating tendencies, a lack of specificity in autobiographical retrieval, ${ }^{16}$ brooding rumination and negative inferential styles ${ }^{17}$ have been found to be predictive of depressive symptoms after childbirth.

Further, depression is characterised by impairments and deviations from normal functioning across a broad range of cognitive domains, for example, attention, attitudes and memory. ${ }^{18}{ }^{19}$ For instance, there is support for a depression-related bias for processing of facial information. ${ }^{20-24}$ Research suggests that mothers with symptoms of PPD rate negative infant faces more negatively compared with non-depressed mothers. ${ }^{25}$ Also, mothers with PPD may less accurately identify happy infant faces compared with healthy controls, ${ }^{26}$ and lower accuracy may be associated with higher levels of maternal depression. ${ }^{27}$ Gil $e t a l^{28}$ found that judgement of facial expressions depended largely on anxiety, but intensity of depressed mood was correlated to judge infant faces as less neutral. Still, research on cognitive biases for facial information in PPD is limited.

The cognitive mechanisms that may mediate the effect of PPD on parenting are not well understood. Rumination in depressed mothers is associated with difficulties in the mother-infant relationship, probably because the depressed mother's focus is mostly on herself and not on the needs of the child. ${ }^{29}$ Müller $e t a l^{30}$ also found that maternal rumination in pregnancy was related to an impaired mother-infant relationship post partum. In addition, parents' processing of infants facial expression is indicated to have an important role for attunement, emotional attachment and emotional regulation. ${ }^{31}$

\section{IMPACT OF PPD ON PARENT-INFANT INTERACTION}

Parental psychopathology such as depression and anxiety may interfere with the parent-infant relationship. ${ }^{32} 33$ This pertains to postnatal mental health and psychopathology in the antenatal period. In fact, a study by Parfitt et $a \hat{l}^{34}$ indicated that prenatal mental health, especially anxiety, was related to parent-infant interaction to a greater extent than postnatal measures.

Although a range of mental health issues are related to parental-child outcomes, the focus of this study will mainly be on depression. Maternal depression may interfere with healthy interactions with the infant by reducing the mother's ability to be sensitively attuned and responsive to her infant's signals and needs. ${ }^{35-38}$ Depressed mothers may also show a more negative (hostile and intrusive) and less responsive parenting style. ${ }^{39}$ Furthermore, they may touch and talk less with their infant and may show more negative facial expressions during face-toface interaction. ${ }^{40}$

Emerging research on the maternal brain and hormones shows that processes underlying parent-infant relationships and parental sensitivity are complex and include markers related to PPD and exposure to childhood adversity (see ref. 41 for a review). There is indication that mothers with depression tend to have poorer mentalisation skills. ${ }^{42}$ Mentalisation can be defined as the capacity to understand the behaviour of oneself and others in terms of underlying mental states and intentions, ${ }^{43}$ whereas reflective functioning is described as an overt manifestation of the capacity to mentalise. ${ }^{44}$ Depressed mothers may have difficulty in reading the affective communication of the infant and responding appropriately. ${ }^{40}$ Accordingly, the ability for affect regulation and interactive coordination is impaired. ${ }^{45} 46$ The capacity to mentalise develops through a child's social interaction with a caregiver who has the ability to understand the child as an individual with a mind. ${ }^{47}$ Thus, a parent's own unresolved adverse childhood experiences might both increase the risk of psychopathology, as well as impact on their own capacity for reflective functioning and ability to bond. ${ }^{44} 48$ Parental reflective functioning may further be related to infant attachment. ${ }^{50} \mathrm{~A}$ recent meta-analysis ${ }^{51}$ supports the existence of an intergenerational transmission of attachment patterns, but concludes that caregiver sensitivity cannot fully explain the transmission and that other moderators are not fully understood. This picture is further complicated by studies suggesting that insecure ambivalent infants often have insecure avoidant mothers and the other way around.$^{52}$ Studies suggest that parental reflective functioning may be one factor in the intergenerational transmission of attachment patterns. ${ }^{53}$

\section{CONSEQUENCES FOR THE CHILD}

It is well documented that maternal depression has an adverse effect on the child's development. ${ }^{40}{ }^{54}$ Children of depressed mothers are more likely to have cognitive, behavioural, emotional and attachment difficulties in childhood. ${ }^{55}$ Disrupted maternal affective communication is linked with attachment disorganisation. ${ }^{57}$ Disorganised attachment is overrepresented in children of depressed mothers ${ }^{55}$ and is associated with internalising and externalising behaviour problems. ${ }^{58} 59$ The risk for adverse outcomes such as poorer 
school adjustment, lower peer social competence and an increased risk for depression persist into later childhood and adolescence. ${ }^{60-62}$

Maternal insensitivity can also influence infant stress-related physiology, as shown by greater activation of the autonomic nervous system. ${ }^{63}{ }^{64}$ Infants of more sensitive mothers show higher resting heart rate variability (HRV) compared with infants of less sensitive mothers. ${ }^{64}$ Heart rate variability is proposed as a marker for stress and health. ${ }^{65}$ Higher HRV is associated with more adaptive coping and emotion regulation, and lower HRV is related to negative outcomes such as depression and anxiety, implicating emotional dysregulation. ${ }^{66}$

Paternal PPD also has important implications. Studies show that even after controlling for maternal depression, depression in fathers in the prenatal and postnatal period is related to negative social, emotional and behavioural outcomes for the child up to 7 years of age. ${ }^{47-69}$ Some studies suggest that PPD in fathers may be especially associated with an increased risk for oppositional defiant and conduct disorders in boys. ${ }^{467}$

\section{PREVENTION AND TREATMENT OF PPD}

PPD in mothers can be conceptualised as a mother-infant relationship disorder. ${ }^{70}$ Thus, interventions improving parent-infant interactions can potentially improve and prevent maternal PPD, as well as improve the trajectories for the children. ${ }^{71} 72$ Such preventive efforts could have important societal implications. A recent report lists the high level of costs associated with maternal perinatal health problems ${ }^{73}$ and concludes that even modest improvements in outcomes as a result of better services would benefit society.

One such relationship-enhancing intervention is The Newborn Behavioral Observation (NBO). ${ }^{74}$ The NBO is a brief, low-cost intervention that can be used in a range of settings. ${ }^{75}$ The intervention can be delivered from around the time of birth, and it is compatible with the regular practice of public health nurses in Norway, and has been implemented as standard care in several regions. The goal of NBO is to sensitise parents to their infant's competencies and to how the newborn baby communicates through body signs, movements, state regulation and responsivity. ${ }^{74}$ Enhanced understanding of how to 'read the baby' can contribute to the development of a positive parent-infant relationship. Compared with usual care, NBO has been found to be related to higher perceived parent-infant interaction quality among parents of high-risk infants. ${ }^{76}$ In addition, results from a pilot study indicated that delivering $\mathrm{NBO}$ as a universal preventive intervention can be related to lower depressive symptomatology in first-time mothers. ${ }^{77}$ By increasing parental sensitivity, the intervention also has the potential to positively affect biomarkers related to infant stress, as indicated by previous studies of attachment-based interventions. ${ }^{78}$ However, research on the effect of NBO as a preventive intervention is scarce, and there is a need for more studies.

\section{AIMS}

The present study has three broad aims:

1. Examine key prenatal and postnatal predictors related to parental functioning: (a) parental depression, anxiety and stress, (b) parental reflective functioning in relation to the infant and (c) parent-infant attachment style.

2. Examine key prenatal and postnatal predictors related to interaction and developmental problems in the child: (a) difficulties in mother-infant interaction in the first 4 months postdelivery and (b) infant's cognitive, communicative and motor development, signs of sustained withdrawal behaviour, and heart-rate variability at 6 months postdelivery.

3. Evaluate the effectiveness of the NBO as a universal preventive intervention delivered in routine practice as compared with standard care, on:

- parental outcomes (depressive symptoms, parenting stress, reflective functioning, attachment to the infant),

- relational outcomes (emotional availability in mother-child interaction) and

- infant outcomes (cognitive, communicative and motor development at 6 months postdelivery, heart-rate variability).

Predictor variables include some well-known vulnerability factors for developing PPD (eg, depression symptoms in pregnancy, adult attachment style, relationship satisfaction and life stress), but the main focus in the observational part of the research project is on cognitive vulnerability factors such as early maladaptive schemas, repetitive negative thinking, rumination, implicit attitudes and cognitive processing of emotionally valenced infant facial information.

\section{METHODS}

\section{Study design}

This is a longitudinal observational study with an intervention. The observational part of the study will use a prospective cohort design. The effect of the intervention will be evaluated using a non-randomised cluster-controlled design, since neither cluster nor individual randomisation is feasible in this routine practice setting. An intervention group receiving NBO (families belonging to two well-baby clinics in Troms $\varnothing$ municipality) will be compared with a control group (families at the remaining four well-baby clinics in Tromsø) receiving care as usual.

\section{Recruitment}

All pregnant women and expecting fathers who speak Norwegian are eligible for inclusion in the study. Between autumn 2015 and autumn 2018 approximately 200 families will be recruited by midwives and by general practitioners (GPs) in the municipality of Tromsø, which is the ninth largest municipality in Norway ( 73000 inhabitants) ${ }^{79}$ There are approximately 1000 births a year in Troms $\varnothing$ municipality. Based on the experiences from a comparable 
study, 'Little in Norway', ${ }^{80}$ the recruitment of 200 families within the project period is considered feasible.

The participants will be recruited in (approximately) week 16 of gestation. At recruitment, women will be given written information about the study and a flyer with an inquiry to be contacted by the research team. If the child's father is not present, the mother is encouraged to inform him about the study. The health worker informs the research team who contacts the women to plan a meeting with them and their partners, preferable between weeks 16 and 22 of gestation. In this meeting, the prospective parents are given detailed information about the study and are invited to sign an informed consent to participate. In addition, at 4 months postdelivery, the parents will be asked to sign an informed consent to obtain birth-related information from the birth record.

\section{Power calculations/statistical analysis}

The sample size is calculated on the basis of differences between the intervention group and the standard care group on the Edinburgh Postnatal Depression Scale (EPDS) maternal score, the Parenting Stress Index (PSI), the Parental Reflective Functioning Scale (PRFQ) and the Maternal Postnatal Attachment Scale (MPAS) 6 weeks postdelivery. Based on the pilot study by Nugent $e t a l^{77}$ and some regression to the mean, we expect a small to medium effect size (f2=0.07). A MANOVA with the four aforementioned outcome variables can detect a difference between the groups with a power of 0.80 given a group size of $n=176$. With an estimated dropout of $10 \%$, a group size of 200 women will be recruited. Sample size is not based on the number of men recruited, as their allocation to the two groups is less predictable than for mothers. The estimation is based on an $\alpha$-level of 0.05 .

\section{Procedure}

For the observational part of the study, assessments will be performed at six time points ( $\mathrm{T}$; table 1): During gestational weeks 16-22 (T1), 24-30 (T2) and 31 (T3), and at 6 weeks (T4), 4 months (T5) and 6 months (T6) postdelivery. For the intervention study, preintervention measures will be collected at T3, postintervention measures at $\mathrm{T} 4$ and follow-up measures at $\mathrm{T} 5$ and $\mathrm{T} 6$. Since the families will receive the first NBO already 2 days postdelivery, no pretest assessment can be obtained for the interaction and infant measures. Hence, analyses of intervention effects will be based on differences between groups at 4 and 6 months postdelivery controlling for relevant covariates. The data are collected using online questionnaires, computerised cognitive tests, videofilmed observations of mother-infant interactions and a standardised test of the child's cognitive, communicative and motor development (Bayley's Scales of Infant and Toddler Development). ${ }^{81}$

\section{The intervention}

The NBO is designed to strengthen the parent-infant relationship and foster a positive alliance between the family and the healthcare provider. It takes 20 to $40 \mathrm{~min}$ to administer and consists of 18 neurobehavioural observations which give a profile of the infant's behavioural repertoire along the dimensions: attentional-interactional, autonomic, motor and state organisation. ${ }^{74}$ How many items that are used in each NBO session depends on the child's state (eg, asleep, awake and calm, or crying). This is in line with the recommendations for use of NBO in Norway ${ }^{82}$ The parents are invited to actively participate in the shared observation of the infant's unique behavioural expressions. Together with the clinician, they can identify techniques for meeting the infant's responses, as well as ventilate feelings and thoughts and ask questions.

The intervention group will receive three NBO consultations: (1) routine care plus NBO at the maternity ward in hospital within 2 days postdelivery; (2) routine home visit plus the NBO by a public health nurse when the infant is 7-10 days old; (3) NBO at the well-baby clinic when the infant is 4 weeks old. The intervention will be conducted by midwives at the University Hospital of North Norway (UNN), and public health nurses in Tromsø municipality. Both the midwives and health nurses are certified in using the NBO. The control group will receive care as usual. Between 7 and 10 days after birth, a public health nurse routinely visits the family at home to evaluate the baby's weight gain and provide guidance on topics such as feeding, crying, sleeping patterns and handling the baby. The parents can also ask questions and voice concerns. Six weeks after birth, the mother and the infant visit the well-baby clinic. Participants in both groups have equal possibilities to seek out other healthcare interventions for their own or their baby's health during the project period.

\section{Instruments \\ Predictor variables/independent variables Sociodemographics}

This includes questions about gender, age, education, marital status, work situation, income, ethnicity, social support, whether pregnancy is wanted, number of pregnancies and children, medication, smoking, and questions about current and previous mental and physical health, as well as help seeking for mental health issues.

\section{Parental cognition and maladaptive schemas}

The Rumination Response Scale $\left(\mathrm{RRS}^{83}\right)$ is a 22-item self-report measure designed to assess responses to depressed mood that are focused on the self, the symptoms, and on possible causes and consequences. The Perseverative Thinking Questionnaire $\left(\mathrm{PTQ}^{84}\right)$ is a 15-item self-report measure developed as a content independent measure of repetitive negative thinking. The Young Schema Questionnaire $\left(\mathrm{YSQ}^{85}\right)$ consists of 90 items measuring maladaptive core beliefs about the self and others, that are rooted in adverse relational experiences in childhood and adolescence. 
Table 1 Study protocol and data collection at different time points during the study

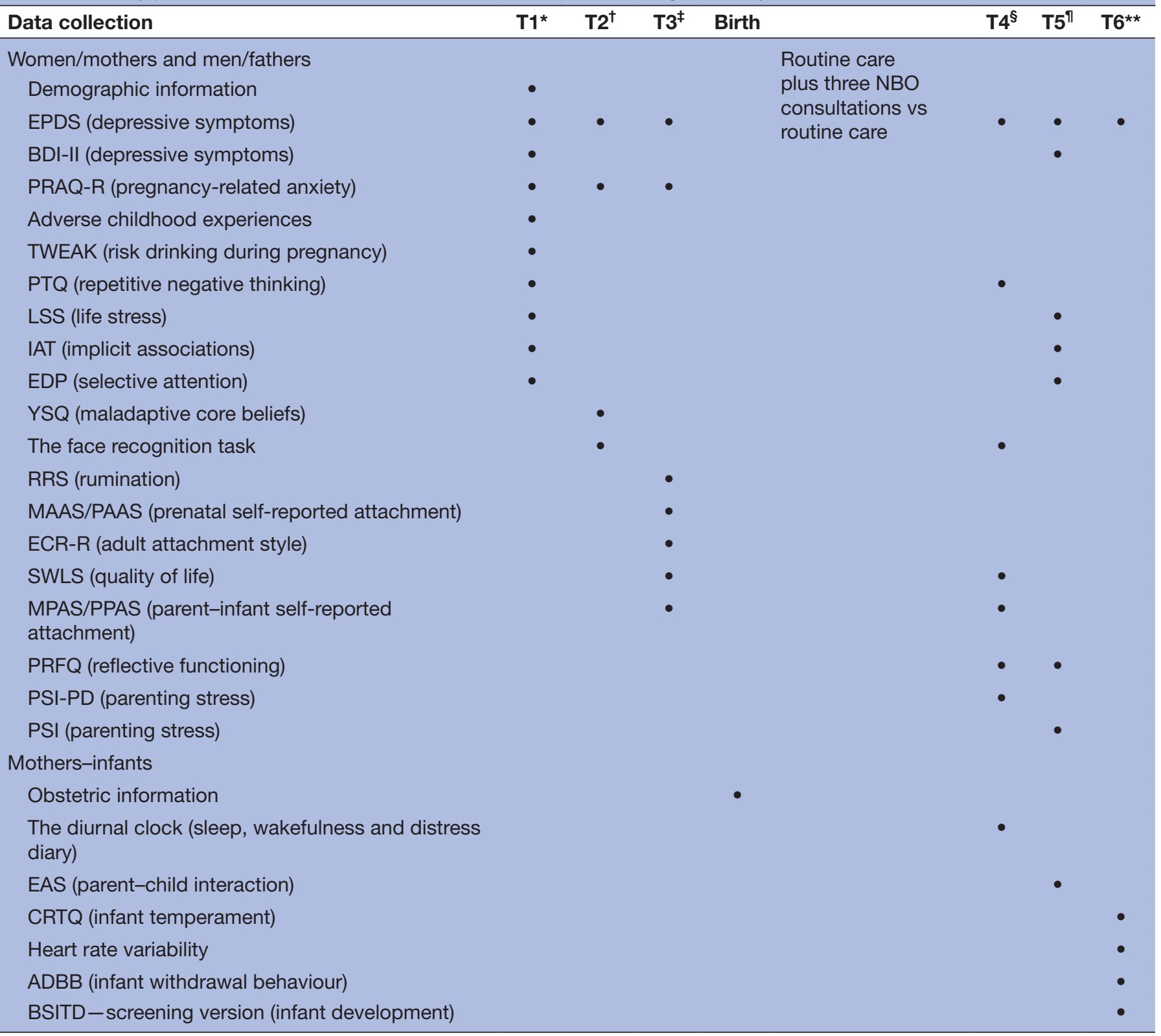

*T1: 16-22 weeks gestation.

†T2: 24-30 weeks gestation.

$\ddagger$ T3/preintervention measures: about 31 weeks gestation.

$\S$ T4/post-intervention measures: 6 weeks post partum.

१T5/follow-up measures: 4 months post partum.

${ }^{*}$ T6/follow-up measures: 6 months post partum.

ADBB, Alarm Distress Baby Scale; BDI-II, Beck Depression Inventory-II; BSITD, Bayley Scales of Infant and Toddler Development; CRTQ, Cameron-Rice Temperament Questionnaire; EAS, Emotional Availability Scale; ECR-R, Experiences in Close Relationships-Revised Questionnaire; EDP, Emotional Dot-Probe; EPDS, Edinburgh Postnatal Depression Scale; IAT, Implicit Associations Test; LSS, Life Stress Scale; MAAS, Maternal Antenatal Attachment Scale; MPAS, Maternal Postnatal Attachment Scale; PAAS, Paternal Antenatal Attachment Scale; PPAS, Paternal Postnatal Attachment Scale; PRAQ-R; Pregnancy-Related Anxiety Questionnaire; PRFQ, Parental Reflective Functioning Scale; PSI, Parenting Stress Index; PSI-PD, Parenting Stress Index-Parent Domain; PTQ, Perseverative Thinking Questionnaire; RRS, Rumination Response Scale; SWLS, Satisfaction With Life Scale; TWEAK, Tolerance, Worried, Eye-opener, Amnesia, Kut down; YSQ, Young Schema Questionnaire.

\section{Parental relationship measures}

Adverse Childhood Experiences $\left(\mathrm{ACE}^{86}\right)$ is a 10 -item measure of emotional, physical and sexual maltreatment and abuse in childhood. The Experiences in Close Relationships-Revised Questionnaire $\left(\right.$ ECR-R ${ }^{87}$ ) is a 36 -item measure of adult attachment style. The ECR-R includes two attachment subscales: avoidance and anxiety. The Maternal Antenatal Attachment Scale $\left(\mathrm{MAAS}^{88}\right.$ ) is a 19-item self-report measure used to assess maternal antenatal bonding to the fetus. The Paternal Antenatal Attachment Scale 
$\left(\mathrm{PAAS}^{89}\right)$ is a 16 -item self-report measure used to assess paternal behaviours, attitudes and feelings towards the fetus.

\section{Measures of parental stress and alcohol abuse}

The Life Stress Scale (LSS) is a subscale of the Parenting Stress Index $\left(\mathrm{PSI}^{90}\right)$ consisting of 19 items measuring stress factors over the last 12 months. The Pregnancy-Related Anxiety Questionnaire (PRAQ- ${ }^{91}$ ) is a 10 -item self-report inventory that assesses three subscales of anxiety that are specific to pregnancy: fear of giving birth, fear of bearing a handicapped child and pregnancy-related concerns about one's appearance. The Tolerance, Worried, Eye-opener, Amnesia, Kut down $\left(\right.$ TWEAK $^{92}$ ) is a five-item self-report scale developed to screen for risk drinking during pregnancy.

\section{Experimental tests}

Parental cognition and a potential depression-related negative bias to infant signals ${ }^{93}$ will be measured with (a) a face recognition task ${ }^{94}$ (b) a single category Implicit Associations Test (IAT) ${ }^{95}$ and (c) a modified Emotional Dot-Probe (EDP) Task. ${ }^{20} 96$ The tests will be administered prepartum and post partum. (A) The face recognition task measures bias towards memory of facial expressions. Pilot data yielded that patients with major depression were better in recognising faces of negative valence than a matched control group (A Bohne, D Nordahl, L ÅAW, et al, unpublished data). (B) The IAT is a well-established measure of implicit attitudes towards the tested categories, for example, objects or persons (including the self). By associating the category of interest with positive and negative words, the resulting difference in reaction times sheds light on a person's attitude. We will use a single-category IAT to investigate attitudes towards infants, using neutral infant images. ${ }^{97}$ (C) The EDP is a test used to assess selective attention. The presentation of emotional stimuli interferes with a spatial task to respond as quickly as possible to the location of a seen target (eg, a dot or cross). In this exogenous cueing task, emotional infant faces $^{97}$ are presented either on the left or right side of the screen. Immediately after a probe is shown. The task is to respond as quickly as possible to the location of the probe. The valence of the stimulus and the mood of the subject biases attention either towards or away from the probe location. ${ }^{989}$

\section{Outcome measures}

Parental measures of depression, stress and quality of life

The Edinburgh Postnatal Depression Scale $\left(\mathrm{EPDS}^{100}\right.$ ) is a 10-item self-report inventory designed to identify women at risk for postnatal depression. Scores on the EPDS range from 0 to 30 , and we use a threshold of 10 or more to define at least probable minor depression. ${ }^{101} 102$ The scale is also validated for use in men. ${ }^{103}$ Depression severity will be assessed with the Beck Depression Inventory-II (BDI-II) ${ }^{104}$ BDI-II is a 21 -item self-report inventory, and scores on the inventory range from 0 to 63 . Total scores will be categorised as follows: 0-13 minimal, 14-19 mild, 20-28 moderate and 29-63 severe. Depressive symptoms during pregnancy assessed with these scales will also be used as predictor variables. The Parenting Stress Index (PSI-FF, third edition $)^{90}$ is a parent self-report measure consisting of 120 items. It is designed to identify potentially dysfunctional parent-child systems and parental stress. The PSI yields a total stress score, and scores for two general domains: Child Domain and Parent Domain (and the LSS (previously described)). Quality of life will be assessed with the Satisfaction With Life Scale (SWLS) which is a 5-item scale measuring global life satisfaction according to the individual's own criteria. ${ }^{105}$ In addition, one item asking participants to rate how happy they feel will be included. ${ }^{106}$

\section{Parent-infant measures}

In order to assess parent-child interaction, we will employ the Emotional Availability Scale (Infancy to Early Childhood Version up to 4 years) (EAS $\left.{ }^{107}\right)$. The EAS is rated on the basis of 15-30 min videotaped episodes of motherinfant play interaction. The Parental Reflective Functioning Questionnaire $\left(\mathrm{PRFQ}^{108}\right)$ is an 18-item self-report questionnaire. It consists of three subscales: pre-mentalising, certainty in mental states and interest and curiosity in mental states. The Maternal Postnatal Attachment Scale $\left(\mathrm{MPAS}^{109}\right.$ ) and The Paternal Postnatal Attachment Scale $\left(\mathrm{PPAS}^{110}\right)$ are 19-item self-report questionnaires for measuring mother-infant/father-infant attachment.

\section{Infant measures}

The Cameron-Rice Temperament Questionnaire $\left(\mathrm{CRTQ}^{111}\right)$ is a 45 -item inventory in which parents are asked to rate their infant's sensitivity, general activity, general intensity, frustration tolerance, adaptability, regularity and soothability. The diurnal clock $\left(\mathrm{DC}^{112}\right)$ is a sleep diary with quantifiable information about sleep, wakefulness and distress over a 24-hour period. Prior to the meeting at 6 weeks postdelivery, the parents are sent two copies of this registration chart and are instructed to complete them over a 48 hours period. The screening test version of Bayley Scales of Infant and Toddler Development (BSITD-Screening version ${ }^{81}$ ) is a short version of the Bayley-III full-scale version. Bayley is a test of cognitive, communicative and motor development widely used for research and clinical purposes. The Alarm Distress Baby Scale $\left(\mathrm{ADBB}^{113}\right)$ is completed based on child behaviour during administration of the Bayley at 6 months. This scale is designed to detect signs of sustained withdrawal behaviour in infants 2-24 months of age.

\section{Biological measures}

Heart rate variability will be measured in mothers and infants during child cognitive testing using wireless unobtrusive electrocardiogram (ECG) equipment. ${ }^{114}$

\section{Fidelity measure}

After each NBO consultation, the interventionist fills out a fidelity form developed for the current study that indicates 
which NBO items were performed, who participated (mother, father, etc.), intervention duration and which themes were discussed. The health workers also rate how they performed the intervention, for example, to which degree they interpreted the baby's signals together with the parents, validated the parents' observations and skills, summed up their observations of the baby's strengths and need for support, and how much they counselled the parents.

\section{ETHICAL CONSIDERATIONS AND DISSEMINATION}

The project follows the standards of the WMA Declaration of Helsinki-Ethical Principles for Medical Research Involving Human Subjects, and the project has been approved by the Regional Committee for Medical and Health Research Ethics in Northern Norway (2015/614). All participants receive both oral and written information about the project. Parents give informed consent for themselves and their infant's participation. Participants receive unique IDs, which they use for questionnaires, cognitive tests and observations. The sheet connecting IDs with names will be securely stored separately from the data. Only authorised personnel from the project will have access to this sheet. We are using a university survey system to ensure secure data storage. All investigators will have access to a data set cleaned of all personal identifiable information. Data sets will be password protected.

During the data collection, it will be emphasised that the participant is free to decline the researcher's involvement. None of the assessments or interventions involves any health risks. As we cooperate with both primary healthcare in Troms $\varnothing$ municipality and the specialist mental healthcare services, and they are well-informed about the study, participants who are in need of more extensive services will be helped to get in touch with the health services for further treatment.

Results from the project will be disseminated in international and national peer-reviewed journals. The results will also be communicated at courses and conferences. In addition, results will be disseminated to the public in various media outlets, and study participants will be informed of the results through the study website (http:// site.uit.no/SIN).

\section{DISCUSSION}

PPD is common among mothers and fathers. There is accumulating evidence that PPD interferes with a healthy interaction between parents and infants, as well as negative developmental outcomes for the child up to several years later. This study aims to increase the knowledge of cognitive risk factors for PPD, interaction difficulties with the child and child development. Such knowledge will be of help in identifying risk families as early as pregnancy. In addition, we aim to investigate if $\mathrm{NBO}$ can be effective in preventing PPD and parent-infant interaction problems.
The main focus of the observation part of the study is to investigate cognitive risk factors for PPD and parentinfant relationship difficulties. Cognition is a predictor that has received relatively little attention in this field of research. Several researchers have suggested that cognitive processing and interpretation of infant signals is central for the parents' attunement to their child. To explore this assumption, we have set up three cognitive tests using pictures of emotional infant faces to measure parents' attention, memory and implicit associations towards infants.

Furthermore, the study expands on the transgenerational perspective by looking at parent's own adverse childhood experiences and cognitive vulnerability as background for their coping with the postpartum period and relating to their infant. Further, we will study how this influences infant stress-related physiology, as measured with heart rate variability, which is proposed as a marker for emotion regulation.

There is a need for interventions with a potential for preventing PPD and improving the parent-infant relationship. This may further promote a healthy development of the child. The NBO is a brief intervention that aims to sensitise parents to their infant's competencies. In the present study, one group of parents will receive three NBO-sessions as a universal preventive intervention during the first 4 weeks after birth, while the control group will receive standard healthcare. We will examine the NBO's potentially positive effects on the parent-infant relationship, as well as in reducing depressive symptoms in the parents.

Finally, although fathers have become more active caregivers for infants in many societies, they are to a lesser degree included in research in this field compared with women. Accordingly, we also include fathers to explore their experiences in this period of transition and examine factors associated with their relationship with the infant.

\section{Author affiliations}

${ }^{1}$ Department of Psychology, Faculty of Health Sciences, UiT The Arctic University of Norway, Troms $\emptyset$, Norway

${ }^{2}$ Division of Mental Health and Addiction, University Hospital of North Norway, Troms $\emptyset$, Norway

${ }^{3}$ Division of Child and Adolescent Health, University Hospital of Northern Norway, Tromsø, Norway

${ }^{4}$ Department of Psychology, Norwegian University of Science and Technology, Trondheim, Norway

${ }^{5}$ Department of Health and Care Sciences, Faculty of Health Sciences, UiT The Arctic University of Norway, Troms $\emptyset$, Norway

Contributors Study concept and design: RSH, DN, GP, IPL, JCT, LKKI and CEAW have all contributed equally to study concept and design. Drafting the manuscript: RSH, DN, GP and CEAW. Critical revision of the manuscript for important intellectual content: RSH, DN, GP, IPL, JCT, LKKI and CEAW.

Funding This study is supported by 'The National Program for Integrated Clinical Specialist and PhD-training for Psychologists' in Norway. This programme is a cooperation between the Universities of Bergen, 0slo, Troms $\emptyset$, the Norwegian University of Science and Technology (Trondheim), the Regional Health Authorities and the Norwegian Psychological Association. The program is funded jointly by The Ministry of Education and Research and The Ministry of Health and Care Services. Also, UiT The Arctic University of Norway has funded the post doc and research assistants who help in the study. Role of the funder/sponsor: The study sponsor had 
no role in the study concept, design and implementation of the study; collection, management, preparation, review, or approval of the manuscript, or the decision to submit the manuscript for publication. Obtained funding: RSH, DN, GP, JCT and CEAW.

Competing interests None declared.

Ethics approval The project has been approved by the Regional Committee for Medical and Health Research Ethics in Northern Norway (2015/614).

Provenance and peer review Not commissioned; externally peer reviewed.

Open Access This is an Open Access article distributed in accordance with the Creative Commons Attribution Non Commercial (CC BY-NC 4.0) license, which permits others to distribute, remix, adapt, build upon this work non-commercially, and license their derivative works on different terms, provided the original work is properly cited and the use is non-commercial. See: http://creativecommons.org/ licenses/by-nc/4.0/

(c) Article author(s) (or their employer(s) unless otherwise stated in the text of the article) 2017. All rights reserved. No commercial use is permitted unless otherwise expressly granted.

\section{REFERENCES}

1. Matthey S, Barnett B, Ungerer J, et al. Paternal and maternal depressed mood during the transition to parenthood. J Affect Disord 2000;60:75-85.

2. O'hara MW, Swain AM. Rates and risk of postpartum depression-a meta-analysis. Int Rev Psychiatry 1996;8:37-54.

3. Reck C, Struben K, Backenstrass M, et al. Prevalence, onset and comorbidity of postpartum anxiety and depressive disorders. Acta Psychiatr Scand 2008;118:459-68.

4. Ramchandani PG, O'Connor TG, Evans J, et al. The effects of pre- and postnatal depression in fathers: a natural experiment comparing the effects of exposure to depression on offspring. $J$ Child Psychol Psychiatry 2008;49:1069-78.

5. Bergström M. Depressive symptoms in new first-time fathers: associations with age, sociodemographic characteristics, and antenatal psychological well-being. Birth 2013;40:32-8.

6. Demontigny F, Girard ME, Lacharité C, et al. Psychosocial factors associated with paternal postnatal depression. J Affect Disord 2013;150:44-9.

7. Serhan N, Ege E, Ayrancı U, et al. Prevalence of postpartum depression in mothers and fathers and its correlates. J Clin Nurs 2013;22(1-2):279-84.

8. Ngai FW, Ngu SF. Predictors of maternal and paternal depressive symptoms at postpartum. J Psychosom Res 2015;78:156-61.

9. Paulson JF, Bazemore SD. Prenatal and postpartum depression in fathers and its association with maternal depression: a metaanalysis. JAMA 2010;303:1961-9.

10. Norhayati MN, Hazlina NH, Asrenee AR, et al. Magnitude and risk factors for postpartum symptoms: a literature review. J Affect Disord 2015;175:34-52.

11. McEwen BS. The neurobiology of stress: from serendipity to clinical relevance. Brain Res 2000;886:172-89.

12. Opacka-Juffry J, Mohiyeddini C. Experience of stress in childhood negatively correlates with plasma oxytocin concentration in adult men. Stress 2012;15:1-10.

13. Ikeda M, Hayashi M, Kamibeppu K. The relationship between attachment style and postpartum depression. Attach Hum Dev 2014;16:557-72.

14. Wee KY, Skouteris H, Pier C, et al. Correlates of ante- and postnatal depression in fathers: a systematic review. J Affect Disord 2011;130:358-77.

15. Evans J, Heron J, Lewis G, et al. Negative self-schemas and the onset of depression in women: longitudinal study. Br J Psychiatry 2005;186:302-7.

16. Hipwell AE, Reynolds S, Pitts Crick E. Cognitive vulnerability to postnatal depressive symptomatology. J Reprod Infant Psychol 2004;22:211-27.

17. Barnum SE, Woody ML, Gibb BE. Predicting changes in depressive symptoms from pregnancy to postpartum: the role of brooding rumination and negative inferential styles. Cognit Ther Res 2013;37:71-7.

18. Gotlib IH, Joormann J. Cognition and depression: current status and future directions. Annu Rev Clin Psychol 2010;6:285-312.

19. Clark DA, Beck AT, Alford BA. Scientific foundations of cognitive theory and therapy of depression. New York, NY: John Wiley \& Sons, Inc, 1999.
20. Joormann J, Gotlib IH. Selective attention to emotional faces following recovery from depression. J Abnorm Psychol 2007;116:80-5.

21. Leppänen JM, Milders M, Bell JS, et al. Depression biases the recognition of emotionally neutral faces. Psychiatry Res 2004;128:123-33.

22. Leyman L, De Raedt R, Schacht R, et al. Attentional biases for angry faces in unipolar depression. Psychol Med 2007;37:393-402.

23. Surguladze SA, Young AW, Senior C, et al. Recognition accuracy and response Bias to happy and sad facial expressions in patients with Major depression. Neuropsychology 2004;18:212-.

24. Joormann J, Gotlib IH. Is this happiness I see? biases in the identification of emotional facial expressions in depression and social phobia. J Abnorm Psychol 2006;115:705-14.

25. Stein A, Arteche A, Lehtonen A, et al. Interpretation of infant facial expression in the context of maternal postnatal depression. Infant Behav Dev 2010;33:273-8.

26. Arteche A, Joormann J, Harvey A, et al. The effects of postnatal maternal depression and anxiety on the processing of infant faces. J Affect Disord 2011;133:197-203.

27. Broth MR, Goodman SH, Hall C, et al. Depressed and well mothers emotion interpretation accuracy and the quality of mother-infant interaction. Infancy 2004;6:37-55.

28. Gil S, Teissèdre F, Chambres $P$, et al. The evaluation of emotional facial expressions in early postpartum depression mood: a difference between adult and baby faces? Psychiatry Res 2011;186(2-3):281-6.

29. Nolen-Hoeksema S, Wisco BE, Lyubomirsky S. Rethinking rumination. Perspect Psychol Sci 2008;3:400-24.

30. Müller D, Teismann T, Havemann B, et al. Ruminative thinking as a predictor of perceived Postpartum Mother-Infant Bonding. Cognit Ther Res 2013;37:89-96.

31. Bistricky SL, Ingram RE, Atchley RA. Facial affect processing and depression susceptibility: cognitive biases and cognitive neuroscience. Psychol Bull 2011;137:998-1028.

32. Field T. Postpartum depression effects on early interactions, parenting, and safety practices: a review. Infant Behav Dev 2010;33:1-6.

33. Feldman R, Granat A, Pariente C, et al. Maternal depression and anxiety across the postpartum year and infant social engagement, fear regulation, and stress reactivity. J Am Acad Child Adolesc Psychiatry 2009;48:919-27.

34. Parfitt Y, Pike A, Ayers S. The impact of parents' mental health on parent-baby interaction: a prospective study. Infant Behav Dev 2013;36:599-608.

35. Cummings EM, Davies PT. Maternal depression and child development. J Child Psychol Psychiatry 1994;35:73-122.

36. Field T. Maternal depression effects on infants and early interventions. Prev Med 1998;27:200-3.

37. Goodman SH, Gotlib IH. Risk for psychopathology in the children of depressed mothers: a developmental model for understanding mechanisms of transmission. Psychol Rev 1999;106:458-90.

38. Murray L, Cooper P. Effects of postnatal depression on infant development. Arch Dis Child 1997;77:99-101.

39. Gelfand D, Teti DM. The effects of maternal depression on children. Clin Psychol Rev 1990;10:329-53.

40. Tronick E, Reck C. Infants of depressed mothers. Harv Rev Psychiatry 2009;17:147-56.

41. Kim P, Strathearn L, Swain JE. The maternal brain and its plasticity in humans. Horm Behav 2016;77:113-23.

42. Kingston D, Tough S, Whitfield H. Prenatal and postpartum maternal psychological distress and infant development: a systematic review. Child Psychiatry Hum Dev 2012;43:683-714.

43. Fonagy $\mathrm{P}$, Steele M, Steele $\mathrm{H}$, et al. The capacity for understanding mental states: the reflective self in parent and child and its significance for security of attachment. Infant Ment Health $J$ 1991;12:201-18.

44. Slade A. Parental reflective functioning: an introduction. Attach Hum Dev 2005;7:269-81.

45. Reck C, Hunt A, Fuchs $T$, et al. Interactive regulation of affect in postpartum depressed mothers and their infants: an overview. Psychopathology 2004;37:272-80.

46. Reck C, Noe D, Stefenelli U, et al. Interactive coordination of currently depressed inpatient mothers and their infants during the postpartum period. Infant Ment Health J 2011;32:542-62.

47. Fonagy $P$, Target $M$. Bridging the transmission gap: an end to an important mystery of attachment research? Attach Hum Dev 2005;7:333-43.

48. Fonagy P, Gergely G, Jurist E, et al; Affect regulation, Mentalization, and the development of the self. New York: Other Press, 2002. 
49. Muzik M, Bocknek EL, Broderick A, et al. Mother-infant bonding impairment across the first 6 months postpartum: the primacy of psychopathology in women with childhood abuse and neglect histories. Arch Womens Ment Health 2013;16:29-38.

50. Fonagy P, Luyten P, Moulton-Perkins A, et al. Development and Validation of a Self-Report measure of mentalizing: the reflective functioning questionnaire. PLoS One 2016;11:e0158678.

51. Verhage ML, Schuengel C, Madigan S, et al. Narrowing the transmission gap: a synthesis of three decades of research on intergenerational transmission of attachment. Psychol Bull 2016;142:337-66

52. Shah PE, Fonagy P, Strathearn L. Is attachment transmitted across generations? the plot thickens. Clin Child Psychol Psychiatry 2010;15:329-45.

53. Slade A, Grienenberger J, Bernbach E, et al. Attachment, and the transmission gap: a preliminary study. Res Hum Dev 2005;7:283-98.

54. Beardslee WR, Versage EM, Gladstone TR. Children of affectively ill parents: a review of the past 10 years. J Am Acad Child Adolesc Psychiatry 1998;37:1134-41.

55. Martins C, Gaffan EA. Effects of early maternal depression on patterns of infant-mother attachment: a meta-analytic investigation. J Child Psychol Psychiatry 2000;41:737-46.

56. Murray $L$. The impact of postnatal depression on infant development. J Child Psychol Psychiatry 1992;33:543-61.

57. Grienenberger JF, Kelly K, Slade A. Maternal reflective functioning, mother-infant affective communication, and infant attachment: exploring the link between mental states and observed caregiving behavior in the intergenerational transmission of attachment. Attach Hum Dev 2005;7:299-311.

58. Groh AM, Roisman Gl, van lizendoorn MH, et al. The significance of insecure and disorganized attachment for children's internalizing symptoms: a meta-analytic study. Child Dev 2012;83:591-610.

59. van lizendoorn $\mathrm{MH}$, Schuengel $\mathrm{C}$, Bakermans-Kranenburg MJ. Disorganized attachment in early childhood: meta-analysis of precursors, concomitants, and sequelae. Dev Psychopathol 1999;11:225-50.

60. Hay DF, Pawlby S, Angold A, et al. Pathways to violence in the children of mothers who were depressed postpartum. Dev Psychol 2003;39:1083-94

61. Kersten-Alvarez LE, Hosman CM, Riksen-Walraven JM, et al. Early school outcomes for children of postpartum depressed mothers: comparison with a community sample. Child Psychiatry Hum Dev 2012;43:201-18.

62. Murray L, Arteche A, Fearon P, et al. Maternal postnatal depression and the development of depression in offspring up to 16 years of age. J Am Acad Child Adolesc Psychiatry 2011:50:460-70.

63. Bosquet Enlow M, King L, Schreier HM, et al. Maternal sensitivity and infant autonomic and endocrine stress responses. Early Hum Dev 2014:90:377-85.

64. Kaplan LA, Evans L, Monk C. Effects of mothers' prenatal psychiatric status and postnatal caregiving on infant biobehavioral regulation: can prenatal programming be modified? Early Hum Dev 2008;84:249-56.

65. Thayer JF, Ahs F, Fredrikson M, et al. A meta-analysis of heart rate variability and neuroimaging studies: implications for heart rate variability as a marker of stress and health. Neurosci Biobehav Rev 2012;36:747-56.

66. Appelhans BM, Luecken LJ. Heart rate variability as an index of regulated emotional responding. Review of General Psychology 2006;10:229-40.

67. Ramchandani P, Stein A, Evans J, et al. Paternal depression in the postnatal period and child development: a prospective population study. Lancet 2005;365:2201-5.

68. Hanington L, Heron J, Stein A, et al. Parental depression and child outcomes--is marital conflict the missing link? Child Care Health Dev 2012;38:520-9

69. Fletcher RJ, Feeman E, Garfield C, et al. The effects of early paternal depression on children's development. Med J Aust 2011;195(11-12):685-9.

70. Cramer B. Are postpartum depressions a mother-infant relationship disorder? Infant Ment Health J 1993;14:283-97.

71. Nylen KJ, Moran TE, Franklin CL, et al. Maternal depression: a review of relevant treatment approaches for mothers and infants. Infant Ment Health J 2006;27:327-43.

72. Paris R, Bolton RE, Spielman E. Evaluating a home-based dyadic intervention: changes in postpartum depression, maternal perceptions, and mother-infant interactions. Infant Ment Health $J$ 2011;32:319-38.

73. Bauer A, Parsonage M, Knapp M, et al; Costs of perinatal mental health problems. London, UK: London School of Economics and Political Science, 2014.
74. Nugent JK, Keefer CH, Minear S, et al; Understanding newborn behavior \& early relationships: the Newborn Behavioral observations (NBO) system handbook: Brookes Pub, 2007.

75. Sanders LW, Buckner EB. The Newborn Behavioral observations system as a nursing intervention to enhance engagement in firsttime mothers: feasibility and desirability. Pediatr Nurs 2006;32:455.

76. McManus BM, Nugent JK. A neurobehavioral intervention incorporated into a state early intervention program is associated with higher perceived quality of care among parents of high-risk newborns. J Behav Health Serv Res 2014:41:381-9.

77. Nugent JK, Bartlett JD, Valim C. Effects of an infant-focused relationship-based hospital and home visiting intervention on reducing symptoms of postpartum maternal depression. Infants \& Young Children 2014;27:292-304.

78. Nicolson S, Judd F, Thomson-Salo F, et al. Supporting the adolescent mother-infant relationship: preliminary trial of a brief perinatal attachment intervention. Arch Womens Ment Health 2013:16:511-20.

79. Statistics Norway. Population and population changes, 1 January 2016: estimated figures;2016 https://www.ssb.no/en/befolkning/ statistikker/folkemengde/aar-berekna/2015-12-17.

80. The little in Norway Study (LiN-study).A longitudinal population study of infant vulnerability and plasticity from pregnancy to age 18 months. The research Council of Norway.Project No.196156;2010.

81. Bayley N. The screening test version of Bayley Scales of Infant and Toddler Development. 3rd ed. San Antonio: Hardcourt Assessment, 2006.

82. Slinning K, Vannebo UT, Landsem I-P, et al. Report by the Norway NBO trainer team Boston Children's Hospital. 2016 http://www. childrenshospital.org/research-and-innovation/research/centers/ brazelton-institute/international/norway.

83. Nolen-Hoeksema S, Morrow J. A prospective study of depression and posttraumatic stress symptoms after a natural disaster: the 1989 Loma prieta Earthquake. J Pers Soc Psychol 1991:61:115-21.

84. Ehring $\mathrm{T}$, Zetsche $\mathrm{U}$, Weidacker $\mathrm{K}$, et al. The Perseverative Thinking Questionnaire (PTQ): validation of a content-independent measure of repetitive negative thinking. J Behav Ther Exp Psychiatry 2011;42:225-32.

85. Young J. 2005. Young Schema Questionnaire-S3. New York: Cognitive Therapy Center of New York.

86. Felitti VJ, Anda RF, Nordenberg D, et al. Relationship of childhood abuse and household dysfunction to many of the leading causes of death in adults. the adverse Childhood experiences (ACE) Study. Am J Prev Med 1998;14:245-58.

87. Fraley RC, Waller NG, Brennan KA. An item response theory analysis of self-report measures of adult attachment. $J$ Pers Soc Psychol 2000;78:350-65.

88. Condon JT. The assessment of antenatal emotional attachment development of a questionnaire instrument. Br J Med Psychol 1993;66 (Pt 2):167-83.

89. Condon JT. The Parental-Foetal Relationship -a Comparison of Male and Female Expectant Parents. J Psychosom Obstet Gynaecol 1985;4:271-84.

90. Abidin RR. 1990. Parenting Stress Index (PSI): Pediatric Psychology Press.

91. Huizink AC, Mulder EJ, Robles de Medina PG, et al. Is pregnancy anxiety a distinctive syndrome? Early Hum Dev 2004;79:81-91.

92. Russel M. New assessment tools for drinking in pregnancy: T-ACE, TWEAK, and others. Alcohol Health and Research World 1994;18:55-61.

93. Webb R, Ayers S. Cognitive biases in processing infant emotion by women with depression, anxiety and post-traumatic stress disorder in pregnancy or after birth: a systematic review. Cognition and Emotion 2014:1-17. (ahead-of-print).

94. Rhodes MG, Anastasi JS. The own-age bias in face recognition: a meta-analytic and theoretical review. Psychol Bull 2012;138:146-74.

95. Greenwald AG, McGhee DE, Schwartz JL. Measuring individual differences in implicit cognition: the implicit association test. $J$ Pers Soc Psychol 1998;74:1464-80.

96. Gotlib IH, Kasch KL, Traill S, et al. Coherence and specificity of information-processing biases in depression and social phobia. $J$ Abnorm Psychol 2004;113:386-98.

97. Maack JK, Bohne A, Nordahl D, et al. The Tromso Infant Faces Database (TIF): development, validation and application to assess parenting experience on clarity and intensity ratings. Front Psychol 2017;8:1-13.

98. Clasen PC, Wells TT, Ellis AJ, et al. Attentional biases and the persistence of sad mood in major depressive disorder. $J$ Abnorm Psychol 2013;122:74-85. 
99. Koster EH, De Raedt R, Goeleven E, et al. Mood-congruent attentional bias in dysphoria: maintained attention to and impaired disengagement from negative information. Emotion 2005;5:446-55.

100. Cox JL, Holden JM, Sagovsky R. Detection of postnatal depression. development of the 10-item Edinburgh Postnatal Depression Scale. Br J Psychiatry 1987;150:782-6.

101. Eberhard-Gran M, Eskild A, Tambs K, et al. The Edinburgh Postnatal Depression Scale: validation in a norwegian community sample. Nord J Psychiatry 2001;55:113-7.

102. Matthey S, Henshaw C, Elliott S, et al. Variability in use of cut-off scores and formats on the Edinburgh Postnatal Depression Scale: implications for clinical and research practice. Arch Womens Ment Health 2006;9:309-15.

103. Matthey S, Barnett B, Kavanagh DJ, et al. Validation of the Edinburgh Postnatal Depression Scale for men, and comparison of item endorsement with their partners. J Affect Disord 2001;64(23):175-84.

104. Beck AT, Steer RA, Brown GK. BDI-II, Beck Depression Inventory: manual. San Antonio, TX: The Psychological Corporation, 1996.

105. Diener E, Emmons RA, Larsen RJ, et al. The satisfaction with Life Scale. J Pers Assess 1985;49:71-5.

106. European Social Survey. European Social survey: source questionnaire amendment 03. $2008 \mathrm{http} / / /$ surveynet.ac.uk/index/ search1099/Ess/4732_2008-2009_quest_capi_papi_face_main.pdf\# search $=\% 22 \% 22$ taking $\% 20$ all\%20t.
107. Biringen Z, Derscheid D, Vliegen N, et al. Emotional availability (EA): theoretical background, empirical research using the EA scales, and clinical applications. Dev Rev 2014;34:114-67.

108. Luyten P, Mayes L, Nijssens L. The parental reflective functioning Questionnaire: development, validation, and clinical application. Infant Ment Health J 2011;31:109.

109. Condon JT, Corkindale CJ. The assessment of parent-to-infant attachment: development of a self-report questionnaire instrument. J Reprod Infant Psychol 1998;16:57-76.

110. Condon JT, Corkindale CJ, Boyce P. Assessment of postnatal paternal-infant attachment: development of a questionnaire instrument. J Reprod Infant Psychol 2008;26:195-210.

111. Cameron JR, Rice DC. Developing anticipatory guidance programs based on early assessment of infant temperament: two tests of a prevention model. J Pediatr Psychol 1986;11:221-34.

112. Sarfi M, Martinsen H, Bakstad B, et al. Patterns in sleepwakefulness in three-month old infants exposed to methadone or buprenorphine. Early Hum Dev 2009;85:773-8.

113. Guedeney A, Fermanian J. A validity and reliability study of assessment and screening for sustained withdrawal reaction in infancy: the alarm distress Baby scale. Infant Ment Health $J$ 2001;22:559-75.

114. Biopac Systems Inc. The Dual Wireless Respiration and Electrocardiogram BioNomadix Transmitter. CA, USA, 2015. 